
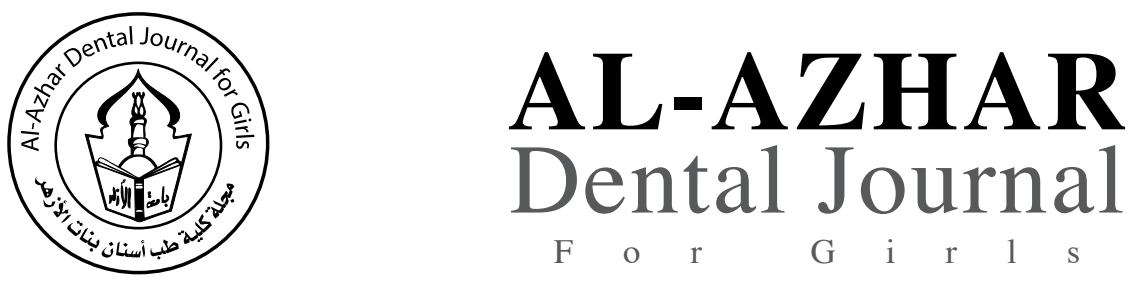

The Official Publication of The Faculty of Dental Medicine For Girls, Al-Azhar University Cairo, Egypt.

ADJ-for Grils, Vol. 4, No. 2, April (2017) — PP. 127:130

\title{
Evaluation of malocclusion severity in Egyptian children having cleft lip and/or palate
}

\author{
Ramia R. Abd El-Rehim ${ }^{(1)}$, Eatimad A. Shoreibah ${ }^{(2)}$ and Mohamed H. Mostafa ${ }^{(3)}$
}

Codex : 15/1704

dentaljournal.forgirls@yahoo.com

Paper extracted from thesis titled Evaluation of malocclusion severity in Egyptian children having cleft lip and/ or palate.

\begin{abstract}
Objectives: evaluate malocclusion severity in Egyptian children having cleft lip and/ or palate. Material and Methods: A sample of 100 Egyptian children. Fifty children representing the cleft lip and /or palate (Group I) and another fifty children free from any systemic disease representing the control group (Group II). Both sexes male and female were included with age ranged from (4 - 15 Years). Each child had subjected to personal data, medical history, assessment of oral health knowledge, attitudes towards dental care, oral health assessment and statistical analysis using SPSS 17. Results: 11 patients (22\%) had definite malocclusion, 15 patients $(30 \%)$ had severe malocclusion, while 14 patients (28\%) had very severe maocclusion. On the other hand, $41(82 \%)$ of the patients in the control group had no abnormalities or normal occlusion. Fisher's exact test revealed that the difference between both groups was statistically significant, except in case of definite malocclusion. Conclusion: The children having cleft lip and / or palate had severe malocclusion and they would need comprehensive orthodontic treatment.
\end{abstract}

\section{INTRODUCTION}

Cleft lip and/or plate (CLP) are one of the most common congenital anomalies. It is includes $65 \%$ of all head and neck anomalies Incidence of cleft lip and/or and palate is 1 in 700 live births ${ }^{(1)}$.

The earliest evidence of the disorder in antiquity was discovered in an Egyptian mummy in 1556, Prerse Franco made the earliest record of cleft lip and palate ${ }^{(1)}$.

Cleft lip;

Cleft palate; Malocclusion;

Dental Aesthetic Index.

1. B.D.S. Cairo University, 2006, Dentist at the Ministry of Interior..

2. Professor of Oral Medicine, Periodontology, Diagnosis and Oral Radiology. Faculty of Dental Medicine (Girls Branch) Al-Azhar University.

3. Assisstant Professor and Head of Pedodontics and Oral Dental Health Department. Faculty of Dental Medicine (Girls Branch) Al-Azhar University. 
The etiology of CLP is still largely unknown. The majority of CLP cases are believed to have a multifactorial in etiology, with several genetic and environmental factors interacting to shift the complex process of morphogenesis toward an abnormality where a cleft can occur. Recently, a meta-analysis showed that maternal factors most often associated with CLP are: tobacco, alcohol, obesity, stressful events, low blood zinc levels, and fever during pregnancy. On the other hand, substitution of folic acid during pregnancy has been found to reduce the risk of CLP ${ }^{(2)}$.

According to the World Health Organization ${ }^{(3)} \mathrm{a}$ cleft lip and /or palate is a dental public health issue because of the oral conditions of the individuals and their psychological, aesthetic and functional impairments.

Malocclusion is defined as an irregularity of the teeth or a malrelationship of the dental arches beyond the range of what is accepted as normal. Although malocclusion is not life threatening. It can be considered as a public health problem due to its high prevalence and prevention and treatment possibilities ${ }^{(4)}$.

The occurrence of malocclusions in subjects with oral clefts favours. The retention of dental plaque on tooth surfaces, predisposing them to different dental diseases such as caries ${ }^{(5)}$.

There is limited evidence of malocclusion characteristics of patients with different types of cleft lip and /or palate. However dental anomalies (e.g. altered tooth dimensions, tooth development, supernumerary teeth), and deficiencies in horizontal and vertical facial development caused by surgical procedures after subjects differently with different oral clefts. Thus it expected that subjects with different of oral clefts present differences in malocclusions ${ }^{(5)}$.

\section{MATERIAL AND METHODS}

The patients of the current study selected from out patient clinic pedodontic department faculty of Dental Medicine Al-Azhar University, Girls ' Branch and Maxillofacial surgery department (Ain Shams) university hospital.

Study Sample: This study was conducted with a sample of 100 Egyptian male and female children with age ranged from (4 - 15 Years).

They were divided into 2 groups:

Group I: Fifty (50) children representing the cleft lip and /or palate.

Group II: Fifty (50) children free from any systemic disease representing the control group.

- Children with any other history of any systemic diseases, facial abnormalities and /or recognized syndromes were excluded.

- Children who had undergone any orthodontic intervention were no considered in this study.

Methods: Every child was subjected to:

(1) Personal, Medical history, Assessment of oral health knowledge and attitudes towards dental care.

(2) Oral health assessment:

- Examination of cleft lip and /or palate took place at the cleft lip and /or palate clinic under adequate illumination using an ordinary chair.

- Both intra and extraoral soft tissue examination were also performed.

- Documentary photographs were also performed.

Assessment of Malocclusion was carried out using the Dental Aesthetic Index (DAI), as prescribed in the World Health Organization $(\mathrm{WHO})^{(3)}$. The collected data were used to calculate standard DAI score using the DAI regression. The resultant sum is the standard DAI score. The regression equation used for calculating standard DAI score is as follows: 
(Missing visible teeth $\mathrm{x} 6)+$ crowding $+($ spacing $)+$ (distema $\times 3)+($ largest anterior maxillary irregularity) + (largest anterior mandibular irregularity) + (Anterior maxillary overjet $\times 2)+($ Anterior - posterior molar relation $\times 3)+13$ (Table 1$)$.

Table (1) Interpretation of Dental Aesthetic Index (DAI) scores

\begin{tabular}{|l|c|c|}
\hline Severity of malocclusion & Treatment need & DAI score \\
\hline $\begin{array}{l}\text { No abnormality or minor } \\
\text { malocclusion }\end{array}$ & $\begin{array}{c}\text { No or slight } \\
\text { need }\end{array}$ & $<25$ \\
\hline Definite malocclusion & Elective & $26-30$ \\
\hline Severe malocclusion & $\begin{array}{c}\text { Highly } \\
\text { described }\end{array}$ & $31-35$ \\
\hline $\begin{array}{l}\text { Very severe or handicapping } \\
\text { malocclusion }\end{array}$ & Mandatory & $>=36$ \\
\hline
\end{tabular}

\section{Statistical analysis}

Analysis of data was performed using SPSS 17 (Statistical Package for Scientific Studies) for Windows. Description of qualitative variables was in the form of number and percentage. Fisher exact test was used for the comparison between study and control groups. Results were expressed in the form p-values that were differentiated into:

Non significant when p-value $>0.05$.

Significant when P-Value $\leq 0.05$.

\section{RESULTS}

Our results were summarized in the following (Table 2 and figure 1).

Table (2) Malocclusion in patients of both groups

\begin{tabular}{|l|c|c|c|}
\hline \multicolumn{1}{|c|}{ Parameter } & Study group & Control & P \\
\hline a- No abnormality or minor malocclusion & $10(20 \%)$ & $41(82 \%)$ & $<0.0001^{*}$ \\
\hline b- Definite malocclusion & $11(22 \%)$ & $6(12 \%)$ & $0.2869^{\text {ns }}$ \\
\hline c- Severe malocclusion & $15(30 \%)$ & $2(4 \%)$ & $0.0009^{*}$ \\
\hline d- Very severe or handicapping malocclusion & $14(28 \%)$ & $1(2 \%)$ & $0.0004^{*}$ \\
\hline Total & $50(100 \%)$ & $50(100 \%)$ & - \\
\hline
\end{tabular}

*significant at $p<0.05, n s=$ non-significant .

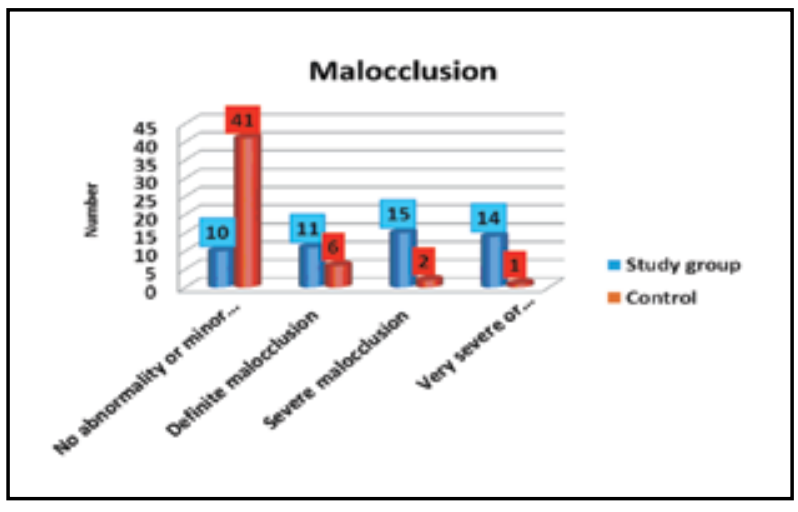

Fig. (1) Malocclusion in patients of both groups

\section{DISCUSSION}

Extensive exploration of available studies revealed very little data associated with malocclusion status using Dental Aesthetic index (DAI) among children having cleft Lip and /or Palate. Most of the studies have assessed dental caries ${ }^{(6)}$, periodontal disease ${ }^{(7)}$ and few of them assessed oral mucosal lesions, developmental defects of enamel and dental Anomalies ${ }^{(6)}$.

There is surprisingly little information on the malocclusion status and treatment needs of cleft lip and / or palate children in Egypt, therefore, 
studies on children with such anomalies are essential to facilitate the integration of oral health and dental preventative regimens into treatment protocols this will result in children implementing desirable habits and oral health practices prior to the provision of surgery and complex treatment.

All selected patients underwent the same surgical protocol for the correction of cleft lip and / or palate and they had not started orthodontic treatment when the study commenced, which allowed adequate comparisons of malocclusion between study group and control.

DAI scale divided the continuous index score defined by the equation in to four malocclusion severity levels was established. Making it easier to use and encouraging its application in orthodontic care programs or malocclusion severity studies ${ }^{(8)}$.

In the Present study, 11 patients $(22 \%)$ had definite malocclusion and, 15 patients (30\%) had severe malocclusion and 14 patients $(28 \%)$ had very severe malocclusion according to Dental Aesthetic index (DAI).

The current study showed that the orthodontic treatment needs among children having cleft lip and I or palate were greater than those of controls, A total of $30 \%$ of cleft subject had a DAI score that indicated treatment was "highly desirable" This value compare with $4 \%$ of controls while a total of $28 \%$ of subjects had very severe malocclusion where the orthodontic treatment need was considered to be a "mandatory" compare to $2 \%$ of controls.

The increased treatment need among cleft subjects can be attributed to basic craniofacial deviations such as delayed growth of the maxilla and relatively proghathic mandible, malposed teeth, morphologically altered teeth or congenitally missing teeth among clefts, which lead to malocclusion, thus increasing the treatment needs among subject ${ }^{(9)}$.

\section{CONCLUSIONS}

The children having cleft lip and / or palate had severe malocclusion and they would need comprehensive orthodontic treatment. Malocclusion problem do manifest early in children having cleft lip and / or palate.

\section{REFERENCES}

- Vanlam FS, Bendeus M and Wong RW. A multidisciplinary team approach on cleft lip and palate management. Hong Kong Dent J. 2007; 4 : 38-45.

- Molina-Solana R, Yanez-Vico R M, Iglesias-Linares A, Mendoza-Mendoza A and Solano-Reina E. Current concepts on the effect of environmental factors on cleft lip and palate Int J Oral Maxillofacial Surgery 2013; 42:177-84.

- WHO. Oral health surveys: basic methods. 4th Ed. Geneva: World Health Organization. 1997.

- Marques LS, Prodeus IA and Ramos Jorge ML, Filogonio CA, Filogonio $\mathrm{CB}$ and Pereiral LJ. Factors Associated with the desire for orthodontic treatment among Brazilian adolescents and their parents. BMC Oral Health. 2009; 9:34-36.

- Parapanisiou V, Gizani S, Makou M and Papagiannoulis L. Oral health status and behaviour of Greek Patients with Cleft Lip and Palate. European archives of Paediatric Dentistry. 2009; 10: 85-89.

- Chapple JR and Nunn JH. The oral health of children with clefts of the lip, palate, or both. Cleft Palate-Craniofacial J. 2001; 38: 525-28

- Lages Em, Marcos B and Pordeus LA. Oral health of individuals with cleft lip, cleft palate, or both. 2004; 41: 59-63.

- Baca-Garcia A, Bravo M, Baca P, Baca A and Junco P. Malocclusions and orthodontic treatment needs in a group of spanish adolescents using the dental Aesthetic index. International Dental J. 2004; 54: 138-42.

- Hongal SG and Ankola A. Malocclusion and treatment needs of cleft lip and / or palate subjects aged between 12 and 18 years. Cleft Palate-Craniofacial J. 2010; 8: 237-42. 